Saunders MNK, Altinay L and Riordan K (2009) The management of post-merger cultural integration: implications from the hotel industry Service Industries Journal $29.10,1359-75$

\title{
THE MANAGEMENT OF POST MERGER CULTURAL INTEGRATION: IMPLICATIONS FROM THE HOTEL INDUSTRY
}

This paper evaluates the effectiveness of post merger management of cultural integration in the hotel industry. Using a mixed method design incorporating a structured card sort of possible feelings and subsequent in-depth interview, data were collected from Head Office employees. Findings highlight the importance of human dynamics of a merger, emphasising the importance of strong leadership, open and honest communication as pre-cursors to mutual learning and suggesting the need for a pre merger cultural audit. Merging two organisations involves the dedication of a remarkable level of resources and activities both before and after the M\&As and yet, a successful outcome is uncertain and it is subject to effective management of cultural integration.

Keywords: mergers and acquisitions, cultural integration, leadership, communication, hotels

\section{INTRODUCTION}

In the last decade there has been a considerable increase in the intensity of Merger and Acquisition activity with each successive year setting a new record for the total value of Mergers and Acquisitions [M\&As] transacted. In 2006 this figure reached deals worth $£ 1,920$ billion worldwide [Rushe, 2006] and deals exceeded $£ 510$ billion in the first three months of 2007 , the busiest first quarter on record [Kennedy, 2007]. Cross-border or international M\&A are particularly prevalent; during the 1990s the value of cross-border M\&A increased five-fold and also looks set to continue [Manchin, 2004]. Within the global hotel industry the level of M\&A activity in the past two years is described as 'whirlwind' [Deloitte, 2006: 2], with private equity firms in particular becoming heavily involved in hotel real estate and M\&A activity.

The hotel industry is widely recognised as operating in a complex, highly fragmented environment [Allison, 2004; Wong and Pang, 2003]. It is 
also closely related to the state of the economy and in recent years a number of environmental shocks such as the rapid emergence of the budget hotel sector, SARS, the 9/11 terror attacks and the Iraq war have triggered cross-border M\&A as a strategy to develop competitiveness [Mintel, 2004]. It is regarded as a common and popular response to globalisation and the changing market environment in the hotel sector of the service industry [Canina, 2001; Kim and Olsen, 1999; Kwansa, 1994; Teare et al., 1997]. In particular, they allow organisations to buy market presence and share, and expand rapidly, and more importantly acquire management expertise in specific areas of need. For example, the acquisition of Holiday Inn brand by Bass Brewery provided knowledge and expertise in the international business, particularly in franchising [Goymour, 1988]. Marriott International and Hilton Hotels acquired Whitbread and Hilton Plc in order to have stronger market presence in the UK market, and also to benefit from the expertise and the accumulated knowledge of these organisations in the UK market [Hotels' Investment Outlook, 2007; Frewin, 2006].

Despite the record-breaking deals and the potential benefits of M\&As, the failure rate of M\&As across all industry sectors continues to increase with some studies citing the failure rate as high as $88 \%$ [Schorg et al., 2004]. Cultural differences between the merging firms is a key element affecting effectiveness of the integration process and consequently the success of M\&As [Lodorfos and Boateng, 2006; Schraeder and Self, 2003]. In the case of crossborder M\&As and where the two organisations are expected to merge structurally, the most favourable strategy is to place a robust cultural 
integration process in order to ensure the alignment delivers the required results [Bijlsma-Frankema, 2001; Carleton and Lineberry, 2004]. If the acquiring organisation disregards all aspects of the target culture including its national culture nuances, then 'acquisition drift' [Lees, 2003: 208] is commonplace. The knowledge and value for which the organisation was initially acquired mitigates, as employees resist the cultural changes forced upon them or choose to leave the organisation altogether.

Although the cultural element in M\&As' integration process has been identified as one of the key issues that may help to explain the failure of many mergers and acquisitions, it is unclear how different approaches to the management of integration affects cultural integration of acquired and acquiring organisations. In particular it is uncertain how cultural integration can be improved post merger in order to enhance M\&As success in the service industry. This paper evaluates the effectiveness of the acquiring organisation's approach to the management of post-merger cultural integration of two international hotel organisations. Cultural integration is an area of concern among service organisations because their chief assets are not factories and equipment but people - employees who develop client relationships and exploit a certain area of expertise for the success of their organisations [Mitleton-Kelly, 2006]. Mergers might lead to the departure of these assets if they feel they have been impacted upon negatively affecting the capability and the competitiveness of the organisations they leave [Lin et al., 2006]. 
Research in hospitality management has traditionally spanned the areas of operations, marketing and accounting [Bessant et al., 2003: 60], neglecting strategic issues which have long term implications for hospitality organisations. In the intervening years, very little research has directly addressed the strategic management and organisational behaviour interface in general and mergers/acquisitions in particular, provoking Litteljohn et al. [2007] to renew the call for research focused on investigating 'the implemented strategy' of hospitality multinationals. In order to provide an initial step in rectifying this deficiency and thus advance the knowledge in the strategic hospitality management literature, the paper examines the empirical findings related to the post merger cultural integration of two hospitality organisations.

\section{LITERATURE REVIEW}

The theoretical and academic interest in M\&A began in the 1960s with the study of M\&A's consequences for competition [Bower, 2004]. In the 1970s theorists turned their attention to diversification and much of the studies involved growth via acquisitions [Bower, 2004]. This was followed in the late 1980s by Porter's seminal text on the performance of acquisitions which detailed the trend for related acquisitions to outperform those that were unrelated due to the advantages of product knowledge transfer and improved economies of scale [Porter, 1987]. Following these studies there was a dramatic increase in the number of M\&A's undertaken, referred to as 'merger mania' by Mirvis and Marks [1992] and in particular there was a significant shift towards horizontal M\&A [Cartwright and Cooper, 1993]. It was at this 
time of heightened activity that the high levels of M\&A failure also became apparent and the literature began to report research into the 'human side' of M\&As [Mirvis and Marks, 1992].

Schraeder and Self [2003] cite organisational culture as the "make or break factor' in mergers and acquisitions and their claims are supported by many others who see culture as the catalyst to successful integration [Carleton and Lineberry, 2004; Styhre et al., 2006]. Organisational culture can be inferred and understood by considering its invisible aspects and visible artefacts which also act to reinforce the culture. These include the beliefs and values, organisational structure, the information and control systems, formal goals and mission statements and myths, legends and stories [Brown, 1998]. Visible artefacts of culture such as its organisational structure, control systems and stories in particular can be managed and manipulated to achieve greater control and effectiveness [Ogbonna and Harris, 2002]. A key study by Watson Wyatt Worldwide [1998] questioned 190 Chief Executive Officers [CEOs] and Chief Finance Officers [CFOs] involved in global acquisitions. They found that, whilst cultural incompatibility was consistently rated as the greatest barrier to post M\&A integration, research into these organisations' cultures was least likely to be included in the due diligence process. Some authors argue that cultural due diligence is critical at the outset of the deal; it is a diagnostic process that ascertains the degree of cultural compatibility between organisations [Cartwright and Cooper, 1993; Lindblom and Koch, 2002]. However, it is worth noting that evaluating the degree of cultural 
compatibility between the organisations requires a thorough understanding of their cultures and this is not a simple straightforward process.

Cultural integration process involves the management of culture in both acquired and acquiring organisations. There should be an in-depth culture audit even before the acquisition to identify any significant differences or similarities between the core values, beliefs, attitudes and managerial style of the target company and the potential acquirer or merger partner [Cartwright and Cooper, 1993; Chatterjee et al., 1992]. It is also recommended that the results of the cultural audit are communicated to the middle management and employees. The results of the cultural audit may be clear at the top of the organisation, but if not clearly communicated to those at middle management and to the employees, this will create ambiguity. Uncertainty results in inevitable culture collisions and battles for cultural supremacy divisionally and interdepartmentally [Badrtalei and Bates, 2007; Birkinshaw, et al., 2000; Styhre et al., 2006].

In addition, organisations need to choose one of the different modes of acculturation for integration [Malekzadeh, and Nahavandi, 1990; Nahavandi and Malekzadeh, 1988; O’Connor, 1995; Pioch, 2007]. Nahavandi and Malekzadeh (1988) identified different modes of acculturation namely integration, assimilation, separation and deculturation. Integration involves structural assimilation of two cultures but little cultural and behavioural assimilation. Organisations preserve their cultural identities. In the case of assimilation, one group adopts the identity and the culture of the other. 
Separation involves preserving one's culture and practices by remaining separate and independent from the dominant group. Acquired company is likely to disintegrate as a cultural entity in the case of deculturation. From the acquired company's point of view, the degree to which members want to preserve their own culture and organisational practices and also the degree to which they are willing to adopt the acquirer's culture determine their preferred mode of acculturation. In the case of the acquirer, their culture and the degree to which the organisation is willing to diversify its strategic focus determine the preferred mode of acculturation [Malekzadeh, and Nahavandi, 1990; Pioch, 2007].

Regardless of the mode chosen, cultural integration, it is argued, should be supported by strategic human resource management (SHRM) [Thornhill et al., 2000]. Cartwright and Cooper [1995] identified four core HRM practices that can contribute significantly to successful integration during post M\&A; management of cultural differences, motivation of employees, retaining the employees and setting them long term vision. Organisations should be tolerant to multiculturalism and create positive attitudes towards the integration among the employees [Birkinshaw et al., 2000]. Intolerance to the acquired culture threatens the cooperation and commitment which are instrumental in determining the acquisition's ultimate success [Chatterjee et al., 1992]. In particular, top down approaches can be more problematic and less successful as such an approach focuses on the process of acquisition rather than on cultural integration and thus results in representational learning rather than behavioural learning [Beer et al., 1990]. 
By contrast bottom-up approaches to facilitate cultural integration are focused on 'task alignment' and emphasise the involvement of the individual. Bottomup cultural change increases empowerment and responsibility for employees throughout all levels of the organisation so that the new culture is actively owned and embraced.

Mitleton-Kelly [2006] states that effective communication and strong leadership also help the management of cultural differences, motivate and retain employees and thus contribute to the cultural integration during post M\&As. There should be a clear and well documented vision and direction for a cultural integration and this has to be effectively and timely communicated to the organisational members. Lodorfos and Boateng [2006] found that the communication is critical in developing trust among the employees of the companies involved and consequently lead to successful integration. Lack of effective communication triggers the problems resulting from cultural differences and creates tensions between the employees. In particular, organisations should pay attention to honesty, consistency and frequency aspects of communication in the integration process [Appelbaum et al., 2000; Papadakis, 2005]. Distrust is inevitable and becomes widespread unless the communication is managed properly.

Fair and transparent organisational climate is important for the development of mutual trust between top management and acquiring and acquired employees. Being truthful, open and forthright in communicating with employees is particularly critical [DeVoge and Shiraki, 2000; Nikandrou 
et al., 2000]. All credibility will be lost if promises are made and later reneged [Appelbaum et al., 2000]. Increased frequency of honest and consistent communication could lead to the reduction of fear [Appelbaum et al., 2000], to the creation of a climate of mutual trust between employees and management. It could also contribute to knowledge sharing between organisations so that the new identity knows what the organisation must know and what capabilities should be developed [Christensen, 2006]. More importantly, communication managed and lead by the leadership could contribute to the creation of a common and clear vision [Bijlsma-Frankema, 2001].

A clear vision and direction help employees concentrate their efforts on strategic issues. Lack of clear vision can harm the cultural integration and result in a weak sense of identity [Appelbaum et al., 2000; Mitleton-Kelly, 2006]. Therefore, leaders need to act as cultural role models in the cultural integration process [Feldman and Spratt, 1999], actively demonstrate the new changed culture through their own, personal changed behaviours [Schein, 2004] and understand the needs and concerns of these individuals while managing the integration process [Mitleton-Kelly, 2006]. The credibility of the leaders, usually defined as a blend of honesty, competence, vision and inspiration, is critical in convincing those affected by changing circumstances [Schraeder and Self, 2003]. They need to possess uniting and leading qualities of management and demonstrate transformational leadership which involves creating a dynamic organisational vision that encourages innovation through bonding individual and collective interests [Pawar and Eastman, 1997]. If these are not properly addressed by the leadership, integration can lead to 
employee dissatisfaction and under performance and thus the organisation will lose its ability to innovate [Christensen, 2006].

\section{RESEARCH DESIGN}

Data were collected within the social realities of employees' reactions to changes associated with acquisition in a hotel organisation that we refer to as "Global Hotels". Global Hotels is an up-scale global hotel chain with its headquarters in the USA and approximately 145,000 employees worldwide. In the 1990's Global Hotels' UK (United Kingdom) division (a franchise) was managed by one of the UK's largest leisure corporations. - referred to in this paper as "LeisureCo". Subsequently LeisureCo exited from the operation, and the ownership of the franchise, by forming what was intended be a two-year joint venture with Global Hotels. Later in that year the joint venture was disbanded as Global Hotels acquired outright ownership of these LeisureCo hotels. Global Hotels immediately began to re-align head office strategies, structures and processes to ensure the acquired operation matched the global model of operation. This included changes to financial, reporting and operating systems as well as job roles, descriptions and reporting structures for

the acquired UK employees. At the time of this research (eighteen months following the acquisition) Global Hotels' UK head office employee turnover rate was the highest level for seven years, with increasing numbers of middle and senior managers leaving, often to work for Global Hotels nearest market sector competitors. 
Research in strategic hospitality management has traditionally been quantitative oriented, leading Olsen and Roper [1998] and Litteljohn et al. [2007] to call for qualitative research offering in-depth analysis of the dynamics of strategy implementation across international borders. In response to this call, a mixed method data collection process derived from Saunders and Thornhill [2004] was used. This integrated two distinct data collection methods: a structured card sort of 40 possible emotions in response to the post M\&A acculturation and a subsequent in-depth interview to explore and explain each respondent's sorting of these and their associated interpretations of these events within the Global Hotels' acquisition context outlined. These data were obtained from a stratified sample of 15 matched pairs drawn from all Global Hotels' head office employees, one member of the pair being drawn from those already employed by Global Hotels at the time of acquisition (acquiring) and the other from those employed by LeisureCo at the time of acquisition (acquired). Within the acquiring group, the majority were US nationals, based in the UK on long-term placements, whilst within the acquired the majority were UK nationals. Stratification ensured that these pairs were drawn from different levels with Global Hotels' structure including board members ( 1 pair) senior managers ( 2 pairs $)$, middle managers ( 7 pairs) and non-management staff including administrative and technical employees (5), resulting in an overall sample size of 30 split into two groups of 15 . Whilst groups of 15 would be unlikely to provide statistical representativeness, research by Guest (2006) indicates that for relatively homogenous groups (such as acquiring employees and acquired employees) a sample size of approximately 12 is sufficient for data saturation to understand commonalties 
The structured card sort was used as the initial means to collect data, drawing directly on the change experience of each participant and providing a means to explore these subsequently through the in-depth interview. Each participant was asked to sort forty cards, each card expressing a single 'feeling' in the active voice; for example 'sceptical' rather than "scepticism". The card sort data collection method required each participant to sort 40 cards containing a single emotion that might be experienced in relation to acculturation. Adapting Saunders and Thornhill [2004] list of responses to organisational change, these were amended to incorporate possible responses to acculturation, cultural alignment and culture change derived from the literatures relating to culture [Elsass and Veiga, 2004; Nahavandi and Malekzadeh, 1988; Marks and Mirvis, 1992].

Each employee was informed that the purpose of the research was to establish and understand her or his 'feelings in relation to the changes as a result of the recent takeover at Global Hotels', it being stressed there were no wrong answers. After assurances of confidentiality and anonymity had been offered and written consent obtained, employees were asked to categorise each card as either 'do not feel' or 'feel to some extent'. Those cards categorised as 'do not feel' were removed and recorded, following completion of this initial sort. Each participant then undertook two further sorts of the remaining cards, having been asked to select those which she or he 'feel strongly' and from these and subsequently to identify the three about which they 'feel most strongly'. 
This card sort allowed data to be collected which recorded each employee's response to each card using a four category ordinal scale. It was followed immediately by an interview of approximately one hour's duration that was structured around each respondent's categorisation of those feelings they felt most strongly, commencing with the three they felt most strongly. This sought to explore and understand the reasons for the categorisation commencing with those that were felt most strongly. This allowed the structure for each interview to be grounded in each respondent's categorisation of their feelings in relation to the $\mathrm{M} \& \mathrm{~A}$, involving a form of respondent validation during the interview [Pidgeon, 1996].

From the card sort and in-depth interview data we sought to explore and make sense of the acquisition in the context of acquired and acquiring respondents' interpretations and their cultural differences. Initially respondents' interview responses related to each of the three feelings they felt most strongly were categorised according to whether they focussed upon favourable, unfavourable or mixed (having both favourable and unfavourable aspects) aspects of the acquisition. This enabled each respondent's overall interpretation of the acquisition to be placed in one of three groups: unfavourable, favourable or mixed. In doing this we sought to develop our analysis in a way that was grounded in our respondents' data and which would be recognised as valid by them.

\section{FINDINGS AND DISCUSSION}




\section{Overall reactions to the acquisition}

Data from the card sort provided an overview of the acquiring and acquired employees' reactions to acquisition. In overall terms, consideration of employees' three mostly strongly felt emotions indicates that respondents were more likely to focus on unfavourable aspects than either favourable or mixed aspects. Overall $81 \%$ of these emotions represented negative feelings in relation to acquisition (See Table 1). However, closer examination of this table shows that there were some differences between the emotions selected by acquired and acquiring employees. Whilst approximately half of acquired employees were most likely to feel frustrated, this proportion rose to four fifths for acquiring employees. In contrast acquired employees emotions appeared to suggest a sense of powerlessness and insecurity. The proportion of employees focussing on favourable aspects when explaining their choice of particular emotions was, although low for both groups, higher for acquiring employees. These employees were drawn from board members and senior managers.

\section{Take in Table 1}

The justification of "most strongly felt" emotions of both groups of respondents were justified by unfavourable aspects of the acquisition and in particular to the large differences between the cultures. It is to these differences between the two times in terms of justifications used by the two groups and their associated implications that we now turn. 
Cultural differences between acquiring and acquired organisations

The findings of the study demonstrated that there were far more unfavourable aspects of merger than the favourable aspects among both acquiring and acquired organisational members. This could be explained by the cultural differences between the acquired and acquiring organisations. The differences which were described as a 'cultural gap' by the informants were mainly commented on by employees of the acquiring organisation, some of whom also appeared to be struggling and "stressed" with the same perception-reality paradigm but who were looking at it from the opposite perspective:

It's been so much harder than we thought for the LeisureCo guys to get on the bus; especially when you consider they were selling the brand anyway for a good few years in the UK before this. I'm not knocking the way they worked before but its like everything now has to be changed, systems, processes, you name it... it's taking a lot longer than we thought and that brings added stress.

(Senior manager, male, acquiring)

There was also a widespread view among the acquired employees that there were cultural differences between the ways these two organisations do business. One of them stated:

They just don't understand the way we work in the UK or the way our customers want to buy. It's just a one-size-fits-all, cookie-cutter approach that is shovelled down our throats every day. (Non management, female, acquired)

There were also clear signs of differences between the decision-making cultures of two organisations. The interviews revealed that acquired employees noted a discernible change had occurred following the M\&A from a high performance, risk accepting culture to one which was risk adverse and where mediocrity was deemed acceptable. Many commented on the considerable 
caution displayed by Global Hotels in terms of decision making ("it takes literally forever to get things done") and the bureaucratic approach adopted in reaching any decision, however insignificant ("everything has to go across [Head Office's] desk; I can't even submit a stationery order on my own anymore"). In addition the organisation appeared to be hold people less accountable for weak performance at employee and managerial level. As one middle manager wryly noted:

If you get your head down and just plod along now this is better than a job in the bank. I could work for the next 20 years and have such an easy ride. Welcome to the world of non-performance management! (Middle manager, male, acquired)

Previous literature highlighted culture as a main barrier to a merger [Lodorfos and Boateng, 2006; Schraeder and Self, 2003]. The findings of the study also demonstrated that regardless of the 'visible' synergies that organisations have in terms of the sector and markets of operations, the opportunity cost of a merger can not be understood unless organisations carry out a thorough internal cultural analysis of each other. One of the motives behind mergers and acquisitions is establishing synergies between the organisations and complementing the merging organisations' expertise in certain areas [Kim and Olsen, 1999]. The findings of this study demonstrated that this could not be achieved unless organisations manage to understand and bring their cultural elements including decision-making and management practices into alignment with each other's.

The findings revealed that organisational marriage was established without developing an understanding about the cultures of each party. 
Contrary to the recommendations made in the literature [Cartwright and Cooper, 1993; Chatterjee et al., 1992], there was no sign of a culture audit in order to identify the differences and similarities between the core values, beliefs and managerial styles in the case of this marriage. In addition, these differences were not communicated to the employees and this led to cultural shocks and disappointments on both sides. More importantly, as identified by Badrtalei and Bates [2007] and Birkinshaw, et al. [2000] this 'arranged marriage' resulted in inevitable culture collusions and battles for cultural supremacy. One of the acquired employees expressed her frustration and resentment by describing the former culture which was focused heavily on achievement and accountability:

I think it's criminal that some of those managers can blatantly get away with being so incompetent. Half of them haven't been near a real hotel operation in years... 90\% of them would've been sacked long before now in LeisureCo. - more to the point they'd never have been given the job in the first place. (Middle manager, female, acquired)

Another informant from the acquired organisation expressed his cynicism and sarcasm towards the situation:

It's a bloody joke; the guy is so out of his depth. He doesn't even know the basics about HR let alone be able to lead us at this time. You have to tell him what to do. Mind you that sums up the whole of Global Hotels! (Non management, male, acquired)

In the literature, there is an ongoing debate about whether culture can be managed or not. This debate appears to be relevant for the mergers and acquisitions as management of culture is crucial both pre and post merger stages [Carleton and Lineberry, 2004; Pioch, 2007]. The findings of the study demonstrated that certain aspects of culture such as decision making approach, management style or certain beliefs could be managed. Organisational 
members could even live with these differences, if these culture nuances could be systematically addressed. In the case of this study, both acquired and acquiring organisations failed the 'cultural audit' test which could be a good preparatory stage for the post-acquisition.

The following theme will provide evidence for the chosen mode of acculturation and discuss the implications of it for the 'marriage'. In particular, it evaluates the effectiveness of communication and leadership in the cultural integration process.

\section{The approach to post-merger management}

For the acquiring organisation, achieving acculturation via assimilation was usually the preferred and intended outcome of the M\&A process. Whilst assimilation was never a formal policy, it was made clear to all the employees that the acquisition of LeisureCo would result in "the Global Hotels Way" dominating organisational life. Despite its apparent failure to materialise, assimilation was carried out in both an overt and covert manner and acquired employees seemed acutely aware of both:

The annual sales conference always used to be about celebration and motivation. This year's was promised as the same but turned out just to be a week of indoctrination into how we should be doing things now. To reinforce the fact, all the awards went to original Global Hotels associates; and the speeches before each award was announced detailed just why they had won it; just to ensure we had really got the message (Middle manager, male, acquired).

At times the assimilation message appeared to be far more severe:

We were in a meeting debating an issue of how to deal with declining sales at a particular hotel. Jim* [middle manager, acquired] was suggesting that in the past he had found a certain method to work well and couldn't we try it now? Mike* [senior manager, acquiring] was silent for a moment and then looked around the table at all of us from 
LeisureCo. "I want you to draw an imaginary red line through everything that LeisureCo. did and stood for". It's time to move on; this is Global Hotels and this is the way we work now". None of us knew how to react - that was definitely telling us - but you could just feel the anger and resentment in the room. (Middle manager, female, acquired)*(Names changed to ensure anonymity)

These findings demonstrate that acquired organisation was not given a choice but forced to adopt the identity, culture and management practices of the acquiring organisation. This is what Nahavandi and Malekzadeh [1988] define as 'assimilation'. However, unlike the arguments of Malekzadeh, and Nahavandi [1990] and Pioch [2007], the degree to which members of the acquired organisation wanted to preserve their own culture and practices and also the degree to which they were willing to adopt the acquirer's culture and practices did not play an influential role of the chosen mode of acculturation. Instead, the acquiring organisation's approach to the management of integration and change was what Beer et al. [1999] define as a top down approach. There was almost no sign of consultation or empowerment to encourage the acquired employees to take the ownership of a newly emerging culture. In contrast, there was a widespread perception among the acquiring organisational members that their approach to management should be embraced by what they called 'newcomers'.

Birkinshaw et al. [2000] highlight the importance of tolerance to differences between cultures and positive attitude towards the acquired employees. Unlike these recommended practices, the dominant attitude has been exclusive. One of the acquiring senior managers stated that "it is only those of us who have been around for years that are what I call true Global Inc.-ers". More importantly, she perceived the acquiring members as 'potential 
threat' and stated that her managers would recognise this and deal with the situation; "I'm sure they'll know what to do about it". Another interviewee was "fearful" that this latest acquisition would upset the core Global Hotel Inc. culture because it would alter the "family way" of life at the organisation:

I'm worried we have overstretched things this time; not from taking on new territories but because how can the newcomers ever really believe and trust in the brand the way we do? I think that's something only really understood and embraced by those of us that are Global Hotels born and bred. (Non management, male, acquiring)

One would expect leadership to act as role models and exploit their leading qualities under these circumstances in order to unite cultures towards a common vision and direction [Christensen, 2006; Feldman and Spratt, 1999; Pawar and Eastman, 1997]. Contrary to these views, the leadership of the acquiring organisation contributed further to the divide between employees. More importantly, besides not acting as role models in the cultural integration process, they did not have credibility in the eyes of acquired employees. There was widespread view among the acquired employees that the acquiring organisation had not been strategic in terms of identifying and selecting those 'role models' who had the potential and skills to manage the integration. For example, the new HR manager appointed by Global Hotels was significantly less qualified and experienced than the former LeisureCo HR director; it was his first management role and his first role at multi unit or head office level. This caused considerable frustration with what was perceived to be an incompetent function and significant anger was directed towards Global Hotels senior management that they had appointed someone so inadequate. 
Lack of strong leadership also led to distrustfulness and confusion among employees of both acquiring and acquired organisations. More importantly it resulted in a lack of strategic direction and dismantled organisational efforts. One interviewee described the situation in the organisation by highlighting the lack of direction and understanding among the organisational members about what the newly formed organisation stands for and what is it that it wants to achieve:

There's so much going on right now. We're being pulled in so many directions at times and that allows less time to ensure everyone's fully on board with us. Some days it's a question of just forging ahead and keeping your fingers crossed that the messages have got through. (Senior manager, female, acquiring)

These findings are in line with the views of Bijlsma-Frankema [2001] and Mitleton-Kelly [2006] who argue that lack of clear vision can lead to cultural and strategic ambiguity, confusion and ultimately hopelessness. Added to these was the issue of lack of honest and consistent communication resulting in 'distrust' among employees. Communication contributes to the development and enforcement of trust among employees [Mitleton-Kelly, 2006; Papadakis, 2005]. However, communication has to be truthful and open [DeVoge and Shiraki, 2000; Nikandrou et al., 2000]. In the case of this study, attempts were made by the acquiring organisation to build up trust and remove the 'us and them' division among the employees by communicating on regular basis through workshops and one-to-ones with each member of LeisureCo's management. During this process, considerable emphasis was placed by Global Hotels on fair and equitable treatment for all. However, the reality appeared to be different with a lot of inconsistencies and lack of fairness and non-transparency in communication. 
It was apparent that the perceived failure of Global Hotels to deliver their promises was being felt harshly by some acquired employees because the reality of working within the Global Hotels culture was far removed from their initial perception of it. A comment from a senior acquired employee who felt "suspicious" of the changes taking place illustrates this:

When the acquisition was first announced so many of us commented on what a positive move it would be. Working for LeisureCo was fantastic but I think most of us had always felt a bit removed at times from the Global Hotels family being just a franchise. Here was an opportunity to truly be part of the bigger organisation with few changes as we were already living the values etc anyway... I think the biggest shock for everyone has been how very different the reality of working for Global Hotels is; it's just so far removed from all of our expectations and perceptions - and not in a good way. (Senior manager, female, acquired).

The failure to deliver on expected promises was also being felt by employees at all levels. For example, a senior manager explained his "angry" feeling:

I remember sitting in the initial sales conference session when it all first began and being told that working for Global Hotels meant I was going to have a remuneration package that rivalled the best in the industry. Yet here we all are some 18 months on; I will not achieve a bonus anywhere near the level I'd attained before, I drive a company car that in LeisureCo. was driven by entrance level sales team members and all the perks like free dry cleaning and meal allowances have been taken away. I'm going backwards! (Senior manager, female, acquired)

Whilst a middle manager justified feeling "powerless": 
They promised better career prospects and better bonus earnings; well that's all well and good if you want to up sticks and move your entire life and family to work with the company in the Middle East or in the USA; but if you want to stay and pursue your career here in the UK then forget it; you're worse off than before. (Middle manager, male, acquired)

The previous literature highlights the benefits of honest and consistent communication for integration as; it could reduce fear, create a climate of mutual trust and also contribute to knowledge sharing, learning and competence development of newly formed organisation [Appelbaum et al., 2000; Christensen, 2006]. None of these seemed to happen in the case of this merger. As a result of hidden agendas and untruthful promises, fear among employees constantly increased and 'lack of trust' dominated every aspect of organisational life. One acquiring manager explained that she was "frustrated" by what she considered to be LeisureCo. employees' constant questioning and "nit picking" at Global Hotels processes:

They question everything, all the time. Why this? Have you thought about doing it this way? Shouldn't we do it this way instead? It drives me mad; it's as if they think they are the only ones who know best. (Middle manager, female, acquiring)

Besides the growing fear and lack of trust, what was alarming with regards to the communication failure was that one of the key rationales of a merger identified by the literature was not addressed. The literature [Kim and Olsen, 1999; Lees, 2003] indicates that mergers allow organisations to develop expertise and skills in the areas where they lack competences. In the case of this merger, there were also clear opportunities for knowledge transfer and learning between two organisations. However, contrary to the suggestions 
made by Christensen [2006], the acquiring organisation chose not to create the channels and the environment to transfer the knowledge and facilitate learning from the acquired organisation. There was a widespread frustration among the acquired employees that developed and tested processes and systems which were seen as 'best practice' in the market were disregarded by the acquiring organisation. One informant was particularly "angry" at the perceived loss of knowledge within the new organisation:

We have spent literally years developing some of our systems and IT to be the very best in the market place; revered by employees and our competitors. How they can just come in and literally throw it all away is just ridiculous; they haven't even bothered to take the time to try and understand how it works and its benefits. I am determined to keep the flag flying for this system (Middle manager, female, acquired).

There were clear signs that the Global Hotels intended cultural alignment strategy was not a success and that, as a result, the M\&A could be classified as failing. When the implications of such an ad hoc management approach to integration was investigated it was found that both acquired and acquiring employees felt stressed and de-motivated, these negative feelings affecting their productivity and performance. In addition, there were many employees both from the acquired and acquiring organisation who had either left or were planning to leave the organisation. One interviewee who expressed "guilt" at the situation said:

I have found these last few months physically and mentally exhausting. Trying to carry on with your own job, which is pressurised enough as it is, but with the added concerns of dealing with the issues that have arisen with the acquisition and knowing I am partly responsible for making sure they are all sorted out is really stressful. I don't think any of us realised when we were first told of the deal and our roles in it just 
what we were letting ourselves in for. (Senior manager, female, acquiring)

Given the amount of investment organisations put into recruitment, staff development, training and forming teams, one can not ignore the high opportunity cost of not managing cultural integration towards creation synergies between the cultures. As revealed within this study, not only was the overall purpose of merger; benefiting from each other's expertise and contributing to the overall financial performance not fulfilled, but also the failure created a potential damage in terms of inefficient use of resources in the service economies of the countries involved.

\section{CONCLUSIONS AND IMPLICATIONS}

This paper aimed to evaluate the effectiveness of an acquiring organisation's approach to the management of post-merger process in the cultural integration of two international hotel organisations. A number of conclusions can be drawn in relation to this. Firstly, it is important to note that there are many international service organisations which look at the idea of merging or acquiring very much from an economic perspective. This has demonstrated itself in those studies that identified the motives of mergers and acquisitions. A number of motives have been identified by the previous studies including expanding market presence and acquiring expertise and internationally recognised products and services (See Bower, 2004; Canina, 2001; Kim and Olsen, 1999). There has always an implicit assumption in these studies that acquiring market presence, expertise and internationally recognised products and services by merging or acquiring would inevitably result in higher organisational performance. Very few studies in the service management field 
and in particular in the hotel sector considered the opportunity costs associated with the integration of two international organisations. This study identified the 'human dynamics' of a merger by providing detailed information about the non-economic factors which influence the integration. Disregarding the noneconomic cultural aspects of the integration means ignoring the real-world complexities of a merger. Merging two organisations involves the dedication of a remarkable level of resources and activities both before and after the M\&As and yet, a successful outcome is uncertain and it is subject to effective management of cultural integration.

Secondly, previous studies also highlighted the management of cultural differences as a challenge for the integration of organisations (See Carleton and Lineberry, 2004; Lakomski, 2001). They recommended that organisations put a robust cultural integration process in place in order to ensure that the alignment is achieved and the new marriage delivers the required results (Bijlsma-Frankema, 2001; Carleton and Lineberry, 2004; Mitleton-Kelly, 2006). However, most of these studies either provided prescriptions for a successful integration by explaining 'how cultural integration could be achieved' through a number of practices and/or provided empirical evidence about the 'best practice' in terms of cultural integration. Very few of these studies provided empirical evidence about the deficiencies and drawbacks of a cultural integration process. This study offered empirical evidence about those practices which appear likely to hinder the cultural integration in a merger. It became apparent that lack of cultural audit and the presentation of findings to the employees pre or during merger would lead culture shocks and collisions 
during the post merger stage. Assimilation as a route to acculturation could lead to faster integration but can not be implemented at the cost of ignoring acquired employees feelings, de-motivation and resistance. Weak leadership and poor communication result in 'distrust' and myopia among the organisational members.

Thirdly, the majority of previous studies investigated the post M\&As integration process from the acquired organisation perspective (Christensen, 2006; Pioch, 2007; Styhre et al., 2006). This study took a holistic approach and reflected upon the views of informants both from acquired and acquiring organisations in identifying the 'disablers' of integration. It became apparent in the study that a top down approach to the management of integration ignoring the real life complexities of managing organisational culture, had not facilitated communication and learning and the building of mutual trust among the employees of both acquiring and acquired organisations. Lack of strong leadership had increased the integration problems affecting the unification of acquiring and acquired employees around a number of common objectives and hindering their ability to concentrate their efforts on strategic long term goals. Communication was also critical in the integration process. However, it has to be transparent, equitable and realistic in terms of its content both for acquired and acquiring employees. Otherwise, organisation wide non-curable problems of 'distrust' and 'unproductive politics' occur, with long term damaging implications for the newly formed organisation. 
This study also offers several practical implications. Hospitality organisations invest huge amount of resources in capacity and capability development. As a result of this investment, they develop internationally recognised and demanded products. More importantly investment helps them to create skills and knowledge pools which enable them to continuously respond to the changing consumer needs and wants. M\&As enhance the capacity of organisations further by marrying their strengths in terms of tangible resources. However, the capability of the organisations will not be strengthen simply by marrying intangible resources - human element without establishing synergies among the employees and creating a platform that will enable them to exploit their skills and expertise. Diagnosing and understanding organisations' cultures even before the integration process appears essential in this endeavour. This will require the collaboration among the leadership of both organisations and will involve a series of consultation with employees at different levels. An external view, such as a consultancy advice can also be taken in identifying the visible and invisible elements of culture.

Effective communication mechanisms should be set in order to deliver transparent, equitable and realistic messages to the employees. Communication should be a two-way communication rather than messages delivered only by the acquiring organisation. One way communication can be perceived rather like an 'order' in such sensitive circumstances. Two-way communication should lead to mutual learning and the use of 'best practice' regardless of the source of it; whether it is from acquiring or acquired 
organisation. It appears that mutual distrust and prejudice is the biggest barrier in front of the integration. Organisations need to consider the sensitivities of the individuals, in particular those of influential figures who have important influence on the informal, shadow organisational systems and have the ability to influence the social integrity of the acquired organisation. In addition to these, organisations strategic direction and targets should tie in closely with clearly defined career pathways and incentives offered for the employees. Such an approach would give employees a clear indication of what their organisation strives to achieve and how their effort will be rewarded should they choose to contribute to the achievement of overall organisational targets. 


\section{REFERENCE LIST}

Allison, S. (2004) Inward investment into the European hotel investment market, Journal of Retail \& Leisure Property, 4(1), pp. 50-59

Appelbaum, H. S., Gandell, J., Yortis, H., Proper, S. and Jobin, F. (2000) Anatomy of a merger: behaviour of organisational factors and processes throughout the pre-during-post stages (part 1), Management Decision, 38(9), pp. 649-661.

Badrtalei, J. and Bates, D. (2007) Effect of Organisational Cultures on Mergers and Acquisitions, International Journal of Management, 24(2), pp. 300-317.

Beer, M., Eisenstat, A., and Spector, B. (1990) The Critical Path to Corporate Renewal. Harvard Business School Press: Boston.

Bessant, J., Birley, S., Cooper, C., Dawson, S., Gennard, J., Gardiner, M., Gray, A., Jones, P., Mayer, C., McGee, J., Pidd, M., Rowley, G., Saunders, J. and Stark, A. (2003) The State of the Field in UK Management Research: Reflections of the Research Assessment Exercise (RAE) Panel, British Journal of Management, 41, pp. 51-68.

Bijlsma-Frankema, K. (2001) On managing cultural integration and cultural change processes in mergers and acquisitions, Journal of European Industrial Training, 25(2/3/4), pp. 192-207.

Birkinshaw, J., Bresman, H. and Hakanson, L. (2000) Managing the postacquisition integration process: How the human integration and task integration processes interact to foster value creation, Journal of Management Studies, 37(3), May, pp. 395-425.

Bower, J. L. (2004) When we study M\&A, what are we learning? in Pablo, A.L. and Javidan, M. (Eds). Mergers and Acquisitions: Creating integrative knowledge. Blackwell: Oxford. pp. 235-255.

Brown, A. (1998) Organisational Culture. Financial Times. Prentice Hall: London.

Canina, L. (2001) Acquisitions in the Lodging Industry: Good news for Buyers and Sellers, Cornell Hotel and Restaurant Administration Quarterly, 42(6), pp. 47-55.

Carleton, J.R. and Linebery, C.S. (2004) Achieving post-merger success. Pfeiffer: San Francisco.

Cartwright, S. and Cooper, L.C. (1995) Organisational marriage: 'hard' versus 'soft' issues?, Personnel Review, 24(3), pp. 32-42. 
Cartwright, S. and Cooper, L.C. (1993) The role of culture compatibility in successful organisational marriage, Academy of Management Executive, 7(2), pp.57-70.

Chatterjee, S., Lubatkin, H.M., Schweiger, M.D. and Weber, Y. (1992) Cultural Differences and Shareholder value in related mergers: Linking Equity and Human Capital, Strategic Management Journal, 13, pp. 319-334.

Christensen, S. K. (2006) Losing Innovativeness: the challenge of being acquired, Management Decision, 44(9), pp. 1161-1182.

DeVoge, S. and Shiraki, J. (2000) People factors: the missing link in merger success, Compensation \& Benefits Management, 16(1), pp.26-32.

Deloitte (2006) Hotel M\&A - No Vacancy?' Available from: http://www.deloitte.com/dtt/cda/doc/content/us_maHotel\%20MA\%20No\%20 Vacancy\%281\%29.pdf [Accessed 06 January 2007]

Elsass, P.M. and Veiga, J.F. (1994) Acculturation in acquired organizations: A force-field perspective, Human Relations, 47, pp. 431-453.

Feldman, M.L. and Spratt, M.F. (1999) Five Frogs on a Log: A CEO's Field Guide to Accelerating the Transition in Mergers, Acquisitions and Gut Wrenching Change. John Wiley \& Sons Ltd: Chichester.

Frewin, A. (2006) Marriott sell-off complete, Caterer and Hotelkeeper, 196(4422), p. 12.

Goymour, D. (1988) Langton on Holiday Inns, Caterer and Hotelkeeper, 179(3530), pp. 34-37.

Guest, G., Bunce, A. and Johnson, L. (2006) How many interviews are enough? An experiment with data saturation and validity, Field Methods, 18(1), pp. 59-82.

Hotels Investment Outlook (2007) Giant Killer, 10(3), pp. 33-36.

Kennedy, S, (2007) M\&A Mania, The Times, Saturday March 31, p.7

Kim, K. and Olsen, M. (1999) Determinants of successful acquisition processes in the UK lodging industry, International Journal of Hospitality Management, 18(3), pp. 285-308.

Kwansa, A.F. (1994) Acquisitions, Shareholder Wealth and the Lodging Sector: 1980-1990, International Journal of Contemporary Hospitality Management, 6(6), pp. 16-20.

Lakomski, G. (2001) Organizational change, leadership and learning: culture as cognitive process, The International Journal of Educational Management, 15(2), pp.68-77 
Lees, S. (2003) Global Acquisitions: Strategic Integration and the Human Factor. Palgrave Macmillan: Basingstoke.

Lin, B., Hung, S. and Li, P. (2006) Mergers and acquisitions as a human resource strategy: Evidence from US banking firms, International Journal of Manpower, 27(2), pp. 126-142.

Lindblom, T. and Koch V.C. (2002) Cross-Border Bank Mergers and Acquisitions in the EU, The Service Industries Journal, 22(4), pp. 41-72.

Litteljohn, D., Roper, A. and Altinay, L. (2007) Territories still to find - the business of hotel internationalisation, International Journal of Service Industry Management, 18(2), pp. 167-183.

Lodorfos, G. and Boateng, A. (2006) The role of culture in the merger and acquisition process: Evidence from the European chemical industry, Management Decision, 44(10), pp. 1405-1421.

Malekzadeh, R.A. and Nahavandi, A. (1990) Making Mergers Work by Managing Cultures, The Journal of Business Strategy, May/June, pp.55-57.

Manchin, M. (2004) Determinants of European cross-border mergers and acquisitions. European Commission: Brussels.

Mintel (2004) Hotels UK: Summary of Key Report Findings. Mintel: London.

Mirvis, P.H. and Marks, M.L. (1992) Rebuilding after the Merger: Dealing with survivor sickness, Organizational Dynamics, 21(2), pp.18-32.

Mitleton-Kelly, E. (2006) Coevolutionary integration: The co-creation of a new organisational form following a merger and acquisition, Coevolutionary Integration E:CO Issue, 8(2), pp. 36-48.

Nahavandi, A. and Malekzadeh, R.A. (1988) Acculturation in Mergers and Acquisitions, Academy of Management Review, 13(1), pp. 79-90.

Nikandrou, I., Papalexandris, N. and Bourantas, D. (2000) Gaining employee trust after acquisition, Employee Relations, 22(4/5), pp. 334-355.

O'Connor, G.N. (1995) The Influence of Organisational Culture on the usefulness of budget participation by Singaporean-Chinese Managers, Accounting, Organisations and Society, 20(5), pp.383-403.

Ogbonna, E. and Harris, L. (2002) Managing organisational culture: insights from the hospitality industry, Human Resource Management Journal, 12(1), pp. 33-53.

Olsen, D. M. and Roper, A. (1998) Research in strategic management in the 
hospitality industry, International Journal of Hospitality Management, 17, 111-124.

Papadakis, M.V. (2005) The roe of broader context and the communication program in merger and acquisition implementation process, Management Decision, 43(2), pp. 236-255.

Pawar, B.S. and Eastman, K.K. (1997) The nature and implications of contextual influences on transformational leadership: A conceptual examination, Academy of Management, 22(1), pp. 80-109.

Pidgeon, N. (1996) Grounded theory: theoretical background In Richardson, J.T.E. (Ed), Handbook of Qualitative Research Methods for Psychology and the Social Sciences, BPS Books: Leicester. pp. 75-85.

Pioch, E. (2007) Business as usual? Retail Employee perceptions of organisational life following cross-border acquisition, International Journal of Human Resource Management, 18(2), pp. 209-231.

Porter, M. (1987) From competitive advantage to corporate strategy, Harvard Business Review, May-June, pp.43-59.

Rushe, D. (2006) All Aboard the M\&A Express, The Sunday Times, December 31, p.5.

Saunders, M.N.K and Thornhill, A. (2004) Trust and mistrust in organisations: an exploration using an organisational justice framework, European Journal of Work and Organisational Psychology, 13(4), pp. 492-515.

Schein, E.H. (2004) Organizational Culture and Leadership. Jossey-Bass: San Francisco.

Schorg, C., Railborn, C.A. and Massoud, M.F. (2004) Using a "Culture Audit" to pick M\&A winners, Journal of Corporate Accounting \& Finance, 15(4), pp. $47-55$

Schraeder, M. and Self, R.D. (2003) Enhancing the success of mergers and acquisitions: an organisatioal culture perspective, Management Decision, 41(5), pp. 511-522.

Styhre, A., Borjesson, S. and Wickenberg, J. (2006) Managed by the other: cultural anxieties in two Anglo-Americanized Swedish firms, International Journal of Human Resource Management, 17(7), pp. 1293-1306.

Teare, R., Eccles, G., Costa, J., Ingram, H. and Knowles, T. (1997) The Granada takeover of Forte: a managerial perspective, Management Decision, 35(1), pp. 5-9. 
Thornhill, A., Lewis, P., Millmore, M. and Saunders, M.N.K. (2000) Managing Change: A Human Resource Strategy Approach. FT Prentice Hall: Harlow.

Watson Wyatt Worldwide (1998) Assessing and Managing Human Capital: a key to maximising the M\&A deal value. Watson Wyatt Worldwide: Bethesda.

Wong, C.S. and Pang, W.L. (2003) Barriers to creativity in the hotel industry perspectives of managers and supervisors, International Journal of Contemporary Hospitality Management, 15(1), pp. 29-37 


\section{LIST OF TABLES}

Table 1: Emotions selected by acquiring and acquired respondents as one of the three about which they felt most strongly

\begin{tabular}{|c|c|c|c|}
\hline Focus & $\begin{array}{l}\text { Acquiring employees } \\
\text { responses }\end{array}$ & $\begin{array}{l}\text { Acquired employees } \\
\text { responses }\end{array}$ & Total \\
\hline $\begin{array}{l}\text { favourable aspects of the } \\
M \& A\end{array}$ & $\begin{array}{l}\text { excited } \\
\text { positive }\end{array}$ & $\begin{array}{l}\text { confident } \\
\text { hopeful } \\
\text { in control } \\
\text { loyal } \\
\text { motivated } \\
\text { optimistic } \\
\text { trusting }\end{array}$ & 9 \\
\hline $\begin{array}{l}\text { both favourable and } \\
\text { unfavourable aspects of the } \\
\text { M\&A (mixed } \\
\text { feelings) }\end{array}$ & $\begin{array}{l}\text { Under pressure (3) } \\
\text { confident } \\
\text { confuse } \\
\text { cynical }\end{array}$ & $\begin{array}{l}\text { cynical } \\
\text { determined }\end{array}$ & 8 \\
\hline $\begin{array}{l}\text { unfavourable aspects of the } \\
\text { M\&A }\end{array}$ & $\begin{array}{l}\text { stressed (8) } \\
\text { frustrated (7) } \\
\text { angry (5) } \\
\text { powerless (3) } \\
\text { threatened (3) } \\
\text { insecure (2) } \\
\text { demoralised (2) } \\
\text { cynical } \\
\text { depressed } \\
\text { determined } \\
\text { hopeless } \\
\text { resigned } \\
\text { stressed } \\
\text { vulnerable }\end{array}$ & $\begin{array}{l}\text { frustrated (12) } \\
\text { hopeless (6) } \\
\text { stressed (5) } \\
\text { angry (4) } \\
\text { suspicious (2) } \\
\text { worried (2) } \\
\text { determined } \\
\text { exhausted } \\
\text { fearful } \\
\text { guilty } \\
\text { threatened }\end{array}$ & 73 \\
\hline Total & 45 & 45 & 90 \\
\hline
\end{tabular}

Note: The 40 emotions from which respondents selected the three felt most strongly are: Angry, Anxious, Confident, Confused, Cynical, Calm, Depressed, Demoralised, Determined, Disengaged, Enthusiastic, Excited, Eager, Exhausted, Fearful, Frustrated, Guilt, Hopeful, Hopeless, In Control, Indifferent, Involved, Insecure, Loyal, Motivated, Optimistic, Powerless, Positive, Relieved, Relaxed, Renewed, Resigned, Stressed, Secure, Suspicious, Threatened, Trusting, Under Pressure, Vulnerable, Worried. Those in italics were not selected by any respondents as one of their three most strongly felt and are not included in this table. 